\title{
Criminalización de la juventud marginal
}

\section{Marie-Astrid Dupret ${ }^{*}$}

\section{Resumen}

Bajo los efectos de la posmodernidad y de la desestructuración social y familiar correlativa, la construcción identitaria del sujeto se ha complicado y la adolescencia se ha transformado en una etapa de la vida muy difícil de transitar y superar, a falta de un ideal de vida y de referencias éticas estructurantes. Para los jóvenes de la marginalidad, esta situación es más compleja aun por las múltiples carencias no sólo materiales sino psicológicas, educativas y culturales que viven. El empujo al actuar, típico de este momento, les lleva a cometer trasgresiones delincuenciales muy graves. La única manera de revertir su destino criminal sería crear políticas de inclusión sociocultural dentro de una nueva institucionalidad simbólica.

\section{Palabras clave}

Adolescencia, criminalización, desimbolización, marginalidad, posmodernidad

\begin{abstract}
Because of the effects of post-modernity and the social and correlative family destructuring, the identity construction of the individual has been complicated and adolescence has become a stage of life which is hard to go through and overcome because they don't have a life ideal and ethical structuring references. For young people of the marginality, this situation is even more complex due to multiple material shortages as well as psychological, educational and cultural deficits which they experience. The strength when they do something, typical of this age, makes them perpetrate very serious criminal transgressions. The only way to revert their criminal destiny would be to create policies of socio-cultural inclusion within a new symbolic institutionality.
\end{abstract}

\section{Key words}

Adolescence, criminalization, desymbolization, marginality, post-modernity.

Forma sugerida de citar: Dupret, Marie-Astrid. 2010. Criminalización de la juventud marginal. Universitas 13. Julio/diciembre. Pp. 69-94.

* Doctora en Filosofia (c) sumereología, psicoanalista, profesora de la Pontificia Universidad Católica del Ecuador. 


\section{Introducción: la marginalidad avanzada}

Si el mundo contemporáneo se preocupa por las grandes tormentas financieras que vive, por los reajustes presupuestarios de los Estados en bancarrota, y también por las catástrofes naturales o no tan naturales del cambio climático, hay un sector cuya realidad está muy olvidada, abandonada y estigmatizada más que nunca; el de la relegación social que alcanza niveles cada vez más altos y un número de personas en continuo crecimiento.

En las últimas décadas, con la aparición de megápolis y de ciudades tentaculares, el paisaje urbano se ha modificado profundamente, con una repartición de los habitantes en zonas diferentes, desde un punto de vista económico y según su origen sociocultural. Ahora una amplia franja de la población más desfavorecida se concentra en barrios bien circunscritos, creando concentraciones de miseria y de desatención estatal, con condiciones de vida cuya precariedad ha aumentado grandemente con las crisis de las últimas décadas. Es en este contexto inédito que se observa una tendencia a la criminalización de la juventud marginal, expresión que se puede entender de dos maneras: la primera hace hincapié en la vía a sentido único reservada al adolescente marginal para encontrar una posición en la sociedad -no hablamos de un lugar de existencia, porque el mercado no tiene espacios disponibles para ellos1; la segunda remite a la mirada que las distintas entidades de la sociedad, el Estado, las Instituciones, o el simple ciudadano- llevan sobre los jóvenes excluidos cada vez más estigmatizados como criminales en potencia, y por lo tanto objetos de medidas represivas y de controles insistentes.

El concepto de 'marginalidad avanzada', propuesto por Loïc Wacquant para referirse a la especificidad de la segregación social en la posmodernidad parece muy fecundo. Como escribe el autor: "El calificativo de 'avanzada' apunta a indicar que estas formas de marginalidad [...] se levantan delante de nosotros: están inscritas en el devenir de las sociedades contemporáneas", y continua el autor, "por consecuencia es urgente diagnosticarlas con el fin de darse los

$1 \quad$ El caso de los Roms en Francia y en otros lugares de Europa es ejemplar de esta situación. 
medios de trazar nuevas vías de intervención pública capaces de bloquear o redirigir las fuerzas estructurales que las engendran. [...]":

Si nuevos mecanismos de incorporación social y política no están establecidos para reintegrar las poblaciones desechadas en aquellos territorios de abandono, se puede esperar que la marginalidad urbana siga extendiéndose y, con ella la violencia de calle, la alienación política, la desertificación organizacional y la informalización de la economía que mina los barrios de relegación de las grandes ciudades de las sociedades avanzadas (Wacquant, 2006: 241).

Muchas son las consecuencias socioculturales y psicológicas de esta situación, agravadas por los discursos consumistas que acompañan el neoliberalismo y por los cambios radicales de las coordenadas de tiempo y espacio de la posmodernidad. Por cierto, la creación de propuestas políticas adaptadas depende de una comprensión sociológica de esta nueva marginalidad pero no hay respuestas eficaces al mal vivir de un grupo social si se desentienden de las cuestiones psíquicas, culturales y educativas correlativas.

En las próximas páginas, los jóvenes de los sectores marginales y las particularidades de su proceso de subjetivación en este ambiente adverso de carencias y de privaciones de muchas índoles centrarán nuestra atención. Más que proponer estadísticas o narrar experiencias de vida particulares, se intentará poner de relieve los rasgos estructurales que se dibujan a través del filtraje de la singularidad de cada caso. Porque dondequiera que se encuentra el adolescente relegado, un barrio periférico de Quito, un ghetto negro de Chicago, el suburbio de París o una favela brasileña, las condiciones de vida y la segregación son similares en la mayoría de sus aspectos y constituyen la causa primordial de la dinámica de violencia y de la delincuencia juvenil grave.

Antes de profundizar la problemática de criminalización de la marginalidad, conviene desviarnos por algunos temas que surcan el desorden y los discursos posmodernos, y que marcan de su impronta el pasaje adolescente, con el fin de entender mejor los impases que constituyen el trasfondo de la vida de una juventud relegada. 


\section{Desorden posmoderno: una identidad en entredicho}

En los tiempos presentes, hay que ser joven. Y ¿quién no es joven? Hay jóvenes menores y jóvenes mayores, y ¡hay mayores jóvenes y mayores no tan jóvenes! Actualmente la categoría de juventud en su máxima extensión va desde los 12 hasta los 29 años, y no tiene ningún valor intrínseco en un plan sociológico, ya que incluye en el mismo rubro a menores que todavía dependen de sus padres y tienen la obligación de estudiar, y de adultos que, en principio, están ya comprometidos en una vida profesional que debería permitirles normalmente sustentar sus necesidades personales así como las de un nuevo hogar. Tampoco refleja un grupo homogéneo desde una perspectiva psicológica, en cuanto suma adolescentes que se acercan a la pubertad o que están atravesando este periodo de cambio fisiológico, el cual determina su capacidad de procreación, un momento crucial en su desarrollo corporal y subjetivo; y también a mayores de edad ya instalados en una manera de vivir adulta tanto en el plan afectivo y relacional como al nivel de la racionalidad.

De modo que este espectro de edades ya no abarca ninguna problemática subjetiva particular y, en realidad, sólo sirve para confundir quien quisiera entender mejor la etapa transitoria de la vida entre la niñez y la adultez que es la adolescencia. La consecuencia más directa de la ocultación de los momentos de estructuración psíquica en función de la edad es la anulación de la dimensión temporal, de modo que el fin de la infancia y el inicio de la adultez se pierden en un continuum borroso. Además, en un mismo movimiento, se elimina la oposición generacional que establecía un ordenamiento cronológico entre padres e hijos, lo que permitía a cada uno situarse dentro de su grupo en relación con sus pares, y diferenciarse del grupo de sus genitores, una discontinuidad esencial para el establecimiento de la identidad de cada sujeto. La consecuencia directa es la pérdida de significancia estructurante de la edad y del valor referencial de las coordenadas filiales.

En los discursos actuales, cabe añadir el desdibujamiento de la diferencia sexual no sólo en la manera de vestirse, no sólo en las opciones profesionales sino en los roles y en los comportamientos. El resultado de esta situación nueva es una fragilización de la organización de la sociedad y en especial de la estructura familiar que deja de ser creadora de vínculos identificatorios. En 
estas condiciones se dificulta la construcción de una identidad en el plan tanto personal como sociocultural, a pesar de constituir un elemento imprescindible en el proceso de subjetivación del individuo y en su posibilidad de apropiación de las palabras de su comunidad, de su historia y de manera general del sentido de su vida.

Varios trabajos sociológicos, antropológicos y estudios de derecho mencionan la decadencia en la época posmoderna de la estructura familiar, que sufre desorganizaciones más o menos fuertes con consecuencias predecibles respecto a las figuras tanto maternal como paternal. Más específicamente, el cuestionamiento a todo lo que remite al padre, paternalismo o patriarcado, ha desvalorizado la paternidad (Dupret, 2003). De ahí la gran confusión que reina actualmente sobre este tema, obliterando la función estructurante de la metáfora paterna -introducida, recordémoslo, por las palabras de una madre que autorice a un hombre a ser padre: "Este es tu hijo"- función doblemente necesaria para separar al infante de su genitora y para insertarle en una sociocultura, en una comunidad simbólica a la cual, más grande, se sentirá pertenecer por pleno derecho, siempre y cuando acepte sus leyes y sus valores esenciales. Con la eliminación del padre y de la oposición generacional, es todo el ordenamiento de la sociedad que está trastocado.

El psicoanalista André Green recuerda tres significaciones principales del término 'identidad': una "noción de permanencia, de mantenimiento de puntos de referencia fijos, constantes, que escapan a los cambios que pueden afectar al sujeto o al objeto en el curso del tiempo"; una "delimitación que asegura la existencia en estado separado, permitiendo circunscribir la unidad, la cohesión totalizadora indispensable a la capacidad de distinción"; y por fin la idea de "relaciones posibles entre dos elementos, a través de la cual se establece la semejanza absoluta que reina entre ellos, permitiendo reconocerlos como idénticos". Sigue el autor: "Estos tres caracteres son solidarios: constancia, unidad, reconocimiento de lo mismo y constituyen las condiciones de la capacidad de conocimiento $[\ldots]$ : Ser, ser uno, reconocer el uno"; uno se da cuenta entonces que: "en una perspectiva psicoanalítica, el sujeto no puede definirse sino por su relación con sus padres", primer elemento que permite a la identidad subjetiva construirse. Ser uno mismo, reconocerse en la alteridad del frente a frente del dos, aceptar la existencia de un tercero, aquí está la base de la posibilidad de 
convivencia social (Green, 1981: 88). A partir del momento en el cual pierden su importancia las categorías estructurales que permitían a cada uno ubicarse en el tablero social, tanto respecto a sus familiares como a sus pares, resulta muy difícil al sujeto sostener una identidad simbólica, identidad yóica en la encrucijada de lo singular y de lo colectivo, identidad fundadora del ser hablante, que le dé la capacidad de responder de una manera mínimamente satisfactoria a la pregunta: ¿Quién soy? -y que le permita actuar según criterios propios de responsabilidad y de autonomía.

Eliminación de las referencias temporales, desaparición de las categorías generacionales, debilitamiento de la diferencia sexual, desestructuración de la familia, las consecuencias de esta situación se manifiestan en la actualidad en el surgimiento de un desorden sociocultural y en la caducidad de los valores éticos $\mathrm{y}$ de los ideales que fundaban tradicionalmente las posibilidades de convivencia pacífica. A cambio, ha surgido un nuevo referente llamado el tercer pariente: es la televisión cuya función de presentadora de modelos de conducta adaptados al mundo contemporáneo y de vehículo de los modos de consumir de moda, es innegable. Notemos, sin embargo, que la televisión no transmite una cosmovisión organizada alrededor de un bien común ni tampoco de un conjunto de prescripciones cuyo fin es asegurar el buen vivir colectivo, sino que presenta los ideales mercantiles del neoliberalismo gracias a un marketing de imagen.

Tal es el mundo en el cual los jóvenes de hoy están convocados a vivir una vida ya no delimitada por alguna exigencia específica. Hoy en nuestra época de consumismo sin límite, los adolescentes de las clases acomodadas están invitados a hacer y escoger lo que les da la gana; como lo nota el psiquiatra francés, Philippe Jeammet (2005: 19): "La situación actual [es] de fluidez, de apertura a todo, sin límites dados de antemano [...]. [Esto] refleja una mentalidad muy extendida en nuestra época -la de dejar un amplio campo de elecciones a los jóvenes [...] y a menudo desde su infancia". En este contexto, cada joven puede escoger su modelo de vida según sus propios anhelos bajo el lema de goce inmediato, goce a cualquier precio (Melman, 2005). No obstante, contrariamente a lo que uno se imagina, esta ausencia de coerción, esta permisividad, lejos de facilitar la estructuración psíquica del adolescente, le complican mucho la travesía de esta etapa de gran importancia para su vida futura y se vuelve muy grande la tentación de quedar en un estado de niño adulto, sin optar por nada 
en particular, toda elección significando una pérdida insoportable. Muchas de las grandes problemáticas de nuestra época, como las adicciones, el suicidio, los casos límites, no encuentran explicaciones si no se toma en cuenta esta situación nueva de desestructuración de las referencias socioculturales y familiares, de la desaparición de los valores éticos, y de imposiciones imaginarias del consumismo.

En medio de este desorden contemporáneo, la adolescencia posmoderna se siente abandonada y sufre dificultades muy grandes en su construcción de una identidad de sujeto adulto y responsable. Escribe René Unda (2010: 56): "La moratoria socio-juvenil es no sólo una fase que se extiende indefinidamente sino que queda indeterminada en razón de que no se conoce qué habrá que cumplir para pasar de la juventud a la adultez".

\section{El pasaje adolescente}

El pasaje adolescente está acompañado por una serie de hechos muy significativos, determinantes en el devenir del sujeto hacia su autonomía. Desde luego, la pubertad es una etapa de importantes transformaciones corporales cuyos efectos son tan reales como visibles, e indica el paso de la criatura infantil e inmadura al individuo fisiológicamente adulto, en condición de asegurar la reproducción de la especie por medio del acto sexual e incluso, en muchas especies, la subsistencia de su prole. Sin embargo, para los animales, la madurez corporal y sexual adviene de modo natural, sin ningún corte respecto a los comportamientos anteriores; porque las nuevas conductas de búsqueda del apareamiento son instintivas y no necesitan un aprendizaje. Al contrario, para los humanos cuyos instintos han sido sesgados por su inclusión en un mundo de palabras y de cultura, el periodo de la pubertad significa fuertes y múltiples cambios afectivos, emocionales, relacionales, sociales, intelectuales, hasta alcanzar un nuevo estatuto sociocultural y una estructuración psíquica adulta. En este sentido se justifica la creación del vocablo adolescencia ${ }^{2}$ para referirse 
a este periodo más o menos largo de transición entre la infancia y la madurez, propio al ser humano.

Por lo menos en lo que se refiere a los varones, no existía sociedad tradicional o primitiva en la cual el paso de la niñez a la adultez no haya sido marcado por una serie de ritos y de costumbres de gran valor simbólico. En efecto no se trataba únicamente de una modificación de estatuto; a menudo este momento significaba un cambio de la manera de inscribirse y de actuar en su sociocultura. El objetivo de los rituales era fomentar el surgimiento de una persona nueva, diferente, desvinculada de las ataduras de la familia de origen, alguien que pueda entablar lazos inéditos con el fin de ocupar un lugar propio y singular en su comunidad. Entre los aspectos más llamativos de los ritos de iniciación cuya superación era necesaria para alcanzar la adultez y por ende la posibilidad de una vida sexual activa, era la insistencia en indicar con claridad el fin de la infancia puesta en escena por la muerte imaginaria del sujeto y la ruptura del vínculo madre-hijo, costumbres que revestían a veces connotaciones muy dramáticas (Eliade: 1992). Desde una perspectiva psicoanalítica, estos rituales ilustraban el fin del periodo edípico cuando los vínculos de los niños con sus padres dejan de ser de dependencia para transformarse en relaciones entre adultos. Esta estructuración progresiva del psiquismo era -y no deja de ser- indispensable para que el sujeto adulto pueda apoyarse en una identidad simbólica que le permita sostener un deseo propio y asumir funciones de responsabilidad en el seno de su grupo social. En la medida que los ritos de iniciación marcaban con claridad el paso de la infancia a la adultez, el adolescente podía apoyarse en una serie de referencias y balizas exteriores a él para facilitar la travesía de este momento contradictorio, ya no niño, todavía no adulto. Pero los ritos de iniciación tradicionales han desaparecido $\mathrm{y}$, con ellos, la posibilidad para los jóvenes de asegurarse la adquisición de una identidad nueva y un reconocimiento social al superar las pruebas impuestas por la comunidad.

Los grandes cambios en el plan físico y orgánico de la adolescencia corresponden también a modificaciones drásticas en lo que concierne la organización del pensamiento y el razonamiento, la manera de actuar y las relaciones con los otros, en particular en el plan de la sexualidad. En esta época, las identificaciones yóicas pasan por avatares sucesivos, como si el joven estuviera probando su imagen y su capacidad de proyección de un deseo propio, desmarcándose 
de los imperativos familiares, está fuertemente solicitada. Como lo escribe la psicoanalista Marie-Antoinette Descargues-Wéry:

Esta confrontación (con el entorno) responde a una necesidad estructural para el adolescente que se está construyendo; marca un momento de pasaje de la infancia hacia una posición de autonomía que se elaborará por el encuentro de la diferencia y por la toma en cuenta del universo relacional que el adolescente explora de manera muy diferente (Descargues-Wéry, 2005: 7).

Además, respecto a la capacidad de pensamiento, surgen nuevas potencialidades 'gracias a la utilización funcional de signo', como lo nota Lev Vygotski, una de las grandes figuras de la psicología rusa, lo que permitirá al adolescente: "someter a su poder sus propias operaciones psíquicas, dominar el curso de sus propios procesos psíquicos y orientar la actividad de aquellos hacia la resolución del problema al cual está confrontado" (Vygotski, 1985: 157). Por su parte, Jean Piaget y Barbet Inhelder subrayan en la adolescencia una evolución de la manera de pensar que pasa de la capacidad de "razonamientos verbales (lógica de las proposiciones)" a la de formar "una serie de esquemas operatorios que aparecen sincrónicamente: operaciones combinatorias, proporciones, dobles sistemas de referencia, esquema del equilibrio mecánico [...], probabilidades multiplicativas, correlaciones, etcétera" (Inhelder y Piaget, 1985: 10).

Así entendida, la adolescencia es mucho más que la aparición, por cierto bien real, de un impulso libídinal, sino que es el teatro de importantes cambios en la manera de percibir el mundo, de reflejarse en él y de reconstruirlo, que se repercuten tanto en la estructura mental del joven como en su comportamiento, en cuanto su actuar se inscribe desde entonces en una dinámica muy específica de afirmación personal. Estirado entre su infancia protegida y familiar por un lado, y un futuro atractivo pero lleno de riesgos y de trampas por el otro, y atrapado en esta paradoja, el joven vive una situación difícil de significar, y aun más confusa a raíz del desorden posmoderno que, al borrar las referencias estructurantes de la autoridad y de las leyes, al hacer desaparecer las marcas simbólicas de la transición de la niñez a la adultez, no facilita su tarea de abrirse 
un espacio propio para dar sentido a su vida y construirse una identidad en el plan a la vez singular y colectivo que le sostenga en su devenir de ciudadano.

A este panorama complejo, cabe añadir la necesidad del adolescente de trasformar en actos sus pensamientos, bajo la presión de pulsiones sexuales avivadas por la pubertad, un hecho conocido desde tiempos muy remotos. El acto en sí reviste un sentido muy específico en esta etapa de la vida, por ser la manera para el joven de manifestar su presencia a través de gestos cuyo valor es casi teatral, gestos cuya visibilidad tanto para uno mismo como para los otros es esencial: es el acto heroico, es la hazaña deportiva, es alcanzar una meta al filo de lo imposible... Gracias a un acto asumido, el joven deja ver en lo real que él existe, por lo menos en la fugacidad del momento, que es dueño de su ser y que ocupa un lugar único en el escenario del mundo. Pero en la sociedad contemporánea que carece de una definición en cuanto a los modelos de conducta aceptables así como en la orientación hacia un ideal común, el actuar se ha vuelto un reto complicado. En estas circunstancias, ocurre no raras veces que el adolescente se siente bloqueado en su intento de expresarse y de articular palabras y gestos, porque no logra determinar una posición de sujeto autónomo, a raíz de sus dificultades en asumir una identidad personal; entonces opta por manifestarse con actuaciones cuyo sentido le escapa; son los acting out, un decir a través de gestos significativos, que se transforman en 'pasajes al acto' cuando se imagina en una situación desesperada y sin salida, cuando cree no tener ningún interlocutor para escucharle. Como lo sintetiza Charles Melman:

Existirían entre los adolescentes aquellos cuyas manifestaciones constituyen acting out, como llamadas de ayuda a este Padre ideal, que expresan una transferencia (una dirección al Otro). Y existirían otros para quienes, al contrario, no hay nada que esperar de nadie, y para quienes el mundo está percibído como un caos en el cual sólo se trata de salvar el pellejo (Melman, 1992: 15).

Desgraciadamente, la desestructuración sociocultural engendrada por el desorden posmoderno priva a muchos jóvenes de la posibilidad de enmarcar sus actuaciones en un escenario valorado por su entorno, y se multiplican los acting out, y sobre todo pasajes al acto, tales como suicidios, accidentes absurdos, in- 
toxicaciones por sobredosis y tantas otras conductas de desafío a la muerte. Sin embargo, cuando el entorno social está todavía suficientemente organizado y receptivo a las inquietudes de la juventud, cuando hay propuestas académicas, formaciones profesionales, deportivas y culturales, cuando maestros y familiares aceptan servir de referencias, el adolescente tiene grandes posibilidades de salir adelante y de encontrar un camino viable para su futuro. No es el caso de los jóvenes cuyo horizonte está cernido por la relegación social.

\section{La adolescencia de la marginalidad}

"Habían todos tenido éxito a su manera, 'vencedores por el sencillo hecho de estar con vida' con algunas monedas en su bolsillo y una sonrisa para el día siguiente que asoma". Este comentario de unos investigadores respecto a un grupo de amigos que habían crecido juntos en el ghetto de Chicago y citado por Wacquant (2006: 21720) muestra que la vida, el simple hecho de estar vivo, no está considerado por estos jóvenes como un derecho sino como una suerte excepcional. En este contexto de penuria máxima en el plan tanto cultural como material, luchar por la supervivencia se convierte entonces en la tarea primordial del sujeto; sólo queda la pulsión de vida al desnudo, un puro real, carente de valores simbólicos.

Desestructuración de las socioculturas bajo el efecto de los discursos posmodernos, eliminación de las etapas de estructuración subjetiva, por lo menos como categorías temporales definidas y caracterizadas, además del empuje desenfrenado al consumo; para el adolescente condenado por la sociedad a vivir excluido, los medios para no caer en la delincuencia son muy limitados, y pensar escapar a un destino de forajido es ilusorio. Además, a las dificultades materiales, se juntan privaciones culturales, educativas y psíquicas, hasta el punto que decidir sobre su propia vida, autonomizarse y liberarse de las coerciones de su contexto social, se vuelven tareas casi imposibles, sobre todo si se añade las múltiples distorsiones del medio familiar, agresiones de toda índole, abusos sexuales y maltratos, secuelas de un alcoholismo crónico, violencias domésticas, sin olvidar el hecho de codearse con la enfermedad y la muerte a diario. Esta suma de vacíos y de carencias constituye el caldo de cultivo de conductas antisociales y psicopáticas (Dupret, 2005). 
Ningún joven que ha crecido en un barrio marginal conoce lo que es tener una habitación propia, ni siquiera lo que se puede llamar un hogar donde se sienta protegido, un lugar de intimidad donde pueda elaborar sentimientos de pertenencia y de reconocimiento, bases para la construcción de la vida subjetiva y el desarrollo de mecanismos psíquicos fundamentales, como las defensas, el control de las pulsiones y de las excitaciones, la elaboración de fantasías tranquilizadoras. Una de las principales causas de la dificultad de socialización del adolescente marginal nace de estas carencias precoces, cuando no se ha consolidado un sentimiento de pertenencia -ser parte de-, orientarse dentro de un espacio acogedor, el Heim en alemán, pertenecer a una familia- tan necesario para la formación del 'Yo'. Observa Boris Cyrulnik, en su libro Bajo el signo del vínculo, que los niños criados dentro de un ambiente familiar estructurado adquieren "la sensación de permanencia del objeto exterior" porque lo reencuentran con cierta regularidad:

Esta estabilidad del mundo exterior, presentada por la persona [con la cual se estableció un vínculo de apego] constituye el zócalo biológico de la identidad, la adquisición del sentimiento de permanencia, el sentimiento de lo estable [...]. Esta ritmicidad exterior [...] desarrolla en él este sentimiento de quedar idéntico cuando varía el entorno. [A cambio] el niño sin familia (organizada) vive en un mundo imprevisible [y no se desarrolla en él] un sentimiento de permanencia. Todo cambio lo bota al desconocido (Cyrulnik, 2005: 270).

Porque, a falta de balizas simbólicas, se dificulta la estructuración psíquica del sujeto y el niño crece entonces, agarrándose a referencias precarias, con una dependencia sin mediación a su madre que se vuelve la única relación existente. Empero este tipo de vínculo no favorece la consistencia identitaria del sujeto, porque la madre, aislada y sin mediación sociocultural, no puede dialectizar la relación con su hijo, a falta de la intervención de un tercero, de una figura paterna que dé lugar a la alteridad desde una posición susceptible de acoger las llamadas de interlocución. De ahí, se observa una gran fragilidad en todo lo que concierne la apropiación del espacio comunitario, en primer lugar la escuela, muy a menudo vivida como (y de hecho) excluyente. 
Además, cuando el infante crece en un entorno desimbolizado, donde las palabras escasean y donde las costumbres heredadas de la tradición han desaparecido, le resulta muy difícil desarrollar su capacidad de lenguaje por lo menos suficientemente para servirle de herramienta en la construcción de una vida anímica de sujeto deseante, una vida fantasmática y emocional, que le sirva de muro de protección frente a un real deshumanizado. Muy a menudo aparecen formas de desarmonía cognitiva y la estructuración del pensamiento queda inhibída ${ }^{3}$.

\section{Desconocimiento de la Ley, violencia y delincuencia}

Una de las consecuencias más singulares de las deficiencias del entorno sociocultural es la dificultad de aprehender la noción de ley, y por ende la diferenciación entre lo permitido y lo prohibído; a la base, la distinción más elaborada entre el bien y el mal. Mentalizar la conducta, darle un contenido simbólico, o sea una dimensión más allá de un real inmediato y sobre todo un valor colectivo en función de una conciencia moral, se vuelve entonces una tarea sumamente complicada. Al nivel arcaico, la ley primordial para el ser de lenguaje es la que le separa de la omnipotencia de su madre, abriéndole de este modo el camino a un deseo de reconocimiento por parte de los otros, dando un sentido a su actuar y buscando un hilo conductor a su vida, cuyo valor se inscribirá dentro de lo colectivo. "El deseo del hombre, es el deseo del Otro", decía Lacan (1966), entendiendo al Otro como el garante simbólico de la cultura y la posibilidad de convivir en paz con los otros. Pero cuando no hay una integración social, cuando el bagaje lingüístico y cultural se limita a lo estrictamente utilitario, cuando la existencia está desprovista de fantasías y de mitologías, el joven encuentra gran dificultad para sostener un deseo estructurante, que le permite construirse un proyecto de vida en el seno de una comunidad. El adolescente se encuentra

3 Así no raras veces, los dibujos de niños de sectores marginales muestran un retraso de un par de años respecto a las producciones gráficas de otros de un medio socioeconómico más acomodado; y este desfase no suele desaparecer con el tiempo si no hay intervenciones adecuadas. 
entonces encerrado en un círculo vicioso cuya salida casi única es la actuación violenta y la delincuencia criminal.

Las palabras de delincuencia y de delito proceden del mismo origen latín, delinquere: faltar, hacer falta (Esposito, 2003: 84-85). ¿Qué es lo que falta entonces a estos jóvenes llevados a cometer actos delincuenciales? Desde una perspectiva psicoanalítica, se responderá que lo que no hay son palabras estructurantes: "Dónde se deshacen las palabras, empieza la violencia", decía Lacan (Lebrun, 2004: 273). A falta de la consolidación de un sentimiento de pertenencia, de un reconocimiento por parte de sus compañeros y de la introyección de valores éticos, a falta de una herencia de palabras y de valores culturales, a falta de la construcción de un fantasma que se despliegue entre el sujeto y su realidad, el impulso a actuar tan característico de la adolescencia se vuelve casi incontrolable, porque permite al sujeto extraerse de un estado de apatía depresiva y orientar su agresividad hacia el exterior y contra los otros, evitando de este modo angustia y sufrimiento, con la excitación transformada en una sensación momentánea de omnipotencia.

Esta exaltación del actuar se observa con particular nitidez en lo sexual, en las violaciones, en las agresiones físicas y en los homicidios: "El acto sexual violento permite a la vez descargar una excitación insostenible, y reconstituir instantáneamente de manera exclusivamente sensorial, y sin representación, un sentimiento de identidad vivido en el cuerpo reunificado por la experiencia sexual", escribe Véronique Lemaitre (2005: 23). En cuanto a la facilidad para matar de los jóvenes de la marginalidad avanzada, no se la puede entender sin vincularla con el vacío de palabras simbolizantes, la ausencia de referencia a un ideal paterno, y la inexistencia de un orden simbólico y de valores éticos, tan típicos del contexto de la exclusión. Al interpretar los homicidios como formas de parricidios, el psiquiatra Schmouchkovitch (1995:345-346) resalta la naturaleza esencialmente dual de la relación al otro en el acto asesino: “Era él o yo', [...] fórmula que expresa tanto la legitimidad del acto homicida como la necesidad imperativa del acto. El acto es inminente: "hay que hacer algo"; recalca el autor: "El asesino [antes de matar] es un sujeto cosificado, humillado: la vergüenza, es la exhibición del desfallecimiento luego del cual él ya no puede erigirse en cuanto sujeto. [...] El sujeto cosificado debe pasar al acto". Este actuar mortífero, en el cual no hay lugar para un lenguaje mediador, es una nueva 
ilustración del fenómeno posmoderno de desimbolización (Dufour, 2007), y de sus consecuencias particularmente trágicas en los sectores de relegación donde ya no cabe ninguna forma de interacción y de intercambio socioculturales.

El tema de la delincuencia criminal es amplio y cuestionador; pero lo dicho anteriormente es suficiente para entender por qué la exclusión social y las carencias en la transmisión de valores culturales, propulsan a los adolescentes hacia actuaciones violentas, a falta de poder mentalizar sus impulsos para darles sentido dentro de una cosmovisión simbólica y de una comunidad que sirva de marco a su universo de vida. Precisamente, en este contexto de exclusión, la pandilla viene a remplazar la estructura sociocultural ausente.

\section{La pandilla, identidad de sustitución e inserción social}

¿Qué es lo que caracteriza las pandillas? Primero la fraternidad que reina allí, es decir un sistema de intercambio fundado sobre el don recíproco [...]. Es una sociabilidad en la cual todo el mundo es semejante. Hay un jefe, en general $[\ldots]$ que sirve de referente a título de ideal, es el más valiente, es aquel que $[\ldots]$ no tiene temor, que no respeta las convenciones, que es capaz de atreverse [...]. Los otros en general son los semejantes (Melman, 1992: 12-13).

Este comentario de Charles Melman es una excelente introducción a la problemática de las pandillas, subrayando su rol esencial como creadoras de una comunidad fundada en lazos fraternales entre pares, pero también organizada alrededor de la personalidad de un pequeño cacique que tiene un poder y derechos especiales, y que sirve de imagen de referencia. De este modo, la pandilla juega un papel psicológico y social de primer plano al dar un marco de integración grupal y un espacio de estructuración identitaria a aquellos jóvenes carentes de vínculos familiares y socioculturales estructurantes:

La única estructura social capaz de integrar al psicópata parece ser la pandilla. Le ofrece una identidad de rol, una protección, una potencia, un estatuto incluso. Sin embargo esta inserción en la pandilla es más precaria de lo que parece a primera vista: las relaciones de dependencia son 
a la vez coercitivas (el adolescente debe constantemente corresponder a su imagen) y frágiles (el adolescente que se distancia de la pandilla está rápidamente rechazado, olvidado). Hay que subrayar que el psicópata raras veces ocupa en estas pandillas un lugar privilegiado, por ejemplo el de cabecilla, e incluso puede ser echado) (Marcelli y Braconnier, 1988: 12-13).

A partir de la adolescencia, y ya desde antes, resulta muy difícil sobrevivir en la calle sin adherirse a una pandilla, sobre todo porque ayuda a asegurar la supervivencia material de sus miembros. Empero la pandilla no es una organización caritativa o cultural, y por lo general su fin es cometer actos delictivos, a menudo en relación con grandes mafias. No obstante, lo que ofrece al joven de la marginalidad es el sentimiento de pertenecer a un grupo. Después de constatar que más de un cuarto de los menores criminales de su estudio habían actuado en acuerdo con los otros, nota Reinhart Lempp (1979: 237-238):

El grupo, la participación a sus acciones y la pertenencia al mismo, tiene para estos jóvenes un alto valor, porque de ordinario fuera de este grupo tienen pocos o ningún lazo afectivo consistente y durable. Precisamente por ello les resulta tan difícil [...] no participar en una acción planeada y apalabrada (por la pandilla).

En el mundo posmoderno, las pandillas y otros grupos de la misma índole se han extendido hasta el punto que los gobiernos se ven obligados a tomar medidas para contrarrestar sus actuaciones, a menudo ligadas directa o indirectamente con la gran delincuencia y los tráficos mafiosos. La pandilla más famosa en Ecuador es la de los 'Latin Kings', originaria de EE.UU. Sin ser la única, según la investigación de Cornelius Zea (2007), existirían aproximadamente 39.000 pandilleros en el país, y 141 pandillas organizadas en Quito. En este contexto no hay que extrañarse de la tendencia muy común a asociar la delincuencia grave y las pandillas, tan atractivas para los adolescentes de sectores relegados. 


\section{Una juventud marginal criminalizada, una justicia policíaca y una policía militarizada}

Cuando se habla de criminalización de la juventud marginal, hay dos maneras de entender esta expresión. La primera remite al hecho de que las condiciones socioculturales en las cuales crecen los jóvenes de sectores relegados les llevan casi ineluctablemente hacia una delincuencia criminal, como lo acabamos de ver. Pero es necesario resaltar también la otra significación de estas palabras que apuntan a la tendencia muy notable en los discursos del mundo actual, oficiales o no, de estigmatizar a los adolescentes de la marginalidad avanzada y vincularles a la criminalidad, hasta el punto que les resulta sumamente difícil escapar a esta etiqueta. Hasta hace poco, el ordenamiento jurídico con sus principios y sus valores éticos sustentaba la vida en comunidad, y definía las leyes que fundamentaban la posibilidad de una convivencia pacífica. Sin embargo, como escribe el magistrado francés J-P. Jean:

Un cambio de perspectiva se está dando en los sistemas de justicia penal [...]. Frente al aumento de la criminalidad y a la demanda de represión de la opinión, las ciencias criminales y el derecho penal dejan de ser disciplinas centradas en el delincuente, su personalidad, el pasaje al acto, la sanción, la reinserción. Con la atención prioritaria dada a las víctimas [...] y a la importancia política del debate sobre la seguridad, la sociedad pide cuentas a la justicia sobre su funcionamiento, sus resultados, su eficacia frente a la recidiva (Jean, 2008: 6).

Más eficiencia en los procesos judiciales y menos espacios para la interpretación y el análisis de los distintos elementos que rodean el acto criminal -o simplemente delincuente-, "la penalización de la sociedad constituye una tendencia cargada del debate político" (Jean, 2008: 6). Este reduccionismo que se observa en los procedimientos judiciales con el acento dado al aspecto objetivo del delito, en contra de una atención a la personalidad del justiciable -el signo remplaza el significante- está ligado a los fenómenos de desinstitucionalización y de desimbolización de la posmodernidad, que permiten al capitalismo neo-liberal imponerse gracias a la desprotección de la persona transformada 
en "sujeto precario, acrítico y 'psicotizante, [...], abierto a todas las fluctuaciones identitarias y, en consecuencia, dispuesto a seguir todas los enchufes mercantiles" (Dufour, 2007: 28-29). No es necesario ser experto en temas legales para notar la degradación de la justicia, que se diluye en reglas específicas, no integradas a una visión de conjunto, y cuya aplicación está a mano de una policía, a veces especializada pero de ningún modo asimilable a una verdadera jurisprudencia, fundada en una cosmovisión sociocultural. La mayoría de las trasgresiones están entonces tratadas de manera mecánica y ya no dependen de la intervención de un profesional, como un procurador o un magistrado, otrora encargados de analizar todos los aspectos del hecho justiciable, sociales, culturales, psicológicos.

Las consecuencias de este cambio de perspectiva sobre las políticas destinadas a los menores infractores son particularmente graves, porque eliminan hasta la mención de los atenuantes de una vida de carencias y de privaciones. Por ejemplo, en las últimas declaraciones de Sarkozy, el Presidente de Francia, respecto a la propuesta de quitar el derecho a la nacionalidad francesa a los jóvenes delincuentes de padres extranjeros cuando alcanzan los 18 años (Le Monde, 31/07/2010), ninguna atención se presta a los casos específicos, sino que se penaliza de la misma manera a todos los adolescentes, que hayan cometido un crimen grave o que sencillamente hayan participado en un hecho delictivo o en una manifestación violenta ${ }^{4}$. Otro ejemplo aún más caricatural (Madar, 2010: 4-5), es el de las escuelas públicas norteamericanas donde la policía fue encargada de remplazar la autoridad educativa, hasta el punto de esposar a un niño de 4 años porque no quería obedecer a su maestro; educadores opuestos a estos procedimientos fueron también interpelados; y en final de cuentas, aunque el saldo de esta experiencia mostró que estas medidas producían violencias nuevas en lugar de disminuir la incidencia de situaciones conflictivas, los alcaldes y otras figuras políticas estimaron que valía la pena mantener la policía en las escuelas públicas por la imagen de 'seguridad' que transmitía este hecho al público en general. Falta poco, en estas circunstancias, para que se mande al 
ejército para poner orden en los planteles educativos en sectores difíciles, bajo la idea que su modelo de funcionamiento sería el más perfecto para domar a los adolescentes más tumultuosos.

La desimbolización posmoderna, en cuanto despoja al mundo de todo valor que no sea mercantil, resta legitimidad a la autoridad institucional como tal y pone en peligro las bases de la convivencia social. En este mundo nuevo de desreglamentación generalizada, la fragilización de las normas éticas, que sostenían hasta hace poco el intercambio y por ende la trama de la sociedad, surge la predominancia de percepciones y fantasías imaginarias en una opinión pública manipulada por los medios de comunicación. Ya no hay un principio fundador, un arché, sino una serie de ocurrencias puntuales, y las leyes se reducen cada vez más a un amontonamiento de reglas no relacionadas entre sí.

Dentro de este contexto de desimbolización posmoderna y de reducción de la justicia a un papel policíaco, conviene interpretar la idea de fundir la cuestión de la delincuencia juvenil y de los adolescentes infractores en el nuevo Código Orgánico de Garantías Penales del Ecuador.

\section{Los menores infractores: ¿una mera especificación dentro del Código Orgánico de Garantías Penales?}

Por cierto, como lo garantiza el nombre de Raúl Zaffaroni ${ }^{5}$ que firma la introducción, nadie puede dudar de la voluntad manifiesta del anteproyecto del Código Orgánico de Garantías Penales de promover una justicia más eficaz y más democrática. Sin embargo, respecto a los adolescentes delincuentes, este anteproyecto adolece de una fuerte dosis de idealización ingenua, que confunde las buenas intenciones de una visión armoniosa de la sociedad con una lectura realista de la sociopolítica posmoderna, sin olvidar las prescripciones emotivas de una opinión pública alarmada por los discursos de moda y los medios de comunicación. Por ende, en este anteproyecto, no aparece ninguna conside-

5 Profesor emérito de la Universidad de Buenos Aires, Argentina. Director del Departamento de Derecho Penal y Criminología de la Universidad de Buenos Aires. Ministro de la Corte Suprema de Justicia de la Nación Argentina. 
ración respecto a las particularidades psicológicas y a las condiciones de vida de los jóvenes relegados que constituyen la gran mayoría de los adolescentes infractores.

En este contexto $-\mathrm{y}$ sin que los redactores del anteproyecto se hayan percatado de este factor- el traspaso del capítulo de los Menores Infractores del Código de la Niñez y Adolescencia al Código Orgánico de Garantías Penales en el Ecuador, responde a una tendencia muy típica de nuestros días de querer categorizar los temas bajo grandes rubros y ya no por una aprehensión estructural de la problemática analizada. De este modo, en el abordaje de las violencias juveniles, se está tomando en cuenta únicamente el hecho trasgresor en su supuesta objetividad, y no al sujeto con sus circunstancias, ni tampoco la significación psíquica del acto cometido. Además, la inserción del tema de los menores infractores dentro del Código Orgánico de Garantías Penales que reúne a todos los ciudadanos mayores y menores de edad, a partir de los 14 años $^{6}$, sigue la corriente que avala una desaparición de la adolescencia como momento específico y crucial en el desarrollo del ser humano.

No cabe duda que la explicación de la conducta de los adolescentes infractores releva mucho más de un estudio psico-social que una cuestión de jurisprudencia. Más aún, el mundo psíquico de aquellos jóvenes de la marginalidad avanzada, con sus impulsos al actuar, corresponde en muchos aspectos al de niños pre-púberes, de sujetos en formación, cambiantes, maleables, más que al de los adolescentes de sectores más acomodados que han tenido la oportunidad de recibir una educación sólida, abierta a un porvenir ciudadano, y por ende deberían estar vinculados al grupo de los niños. La inclusión de los jóvenes infractores en el Código Orgánico de Garantías Penales, iría en contra de este hecho y facilitaría enormemente una decisión judicial que autorice tramitar el caso de un adolescente marginal como si fuera adulto ${ }^{7}$, mientras que, al quedar

6 Por ejemplo, uno se pregunta qué criterio justifica la edad de 14 años como el paso de la niñez a la adolescencia y, de ahí, la capacidad del joven de responsabilizarse de sus actos (pp.92-93 del Anteproyecto del Código Orgánico de Garantías Penales - versión de diciembre 2010).

7 Este tipo de decisión judicial ya se está tomando en varios países, a partir de criterios que no tienen en cuenta en absoluto el historial psico-social del joven. 
el menor protegido por el Código de la Niñez y Adolescencia, resultaría mucho más complicado tratarlo como adulto desde una perspectiva judicial ${ }^{8}$.

Este cuestionamiento al anteproyecto del Código Orgánico de Garantías Penales, no significa en absoluto que el Código de la Niñez y Adolescencia, tal como está en la actualidad, no deba ser renovado y reorganizado en la parte referente a los menores infractores; bien al contrario convendría mejorarlo en sus aspectos tanto jurídicos como educativos, armonizarlos con los principios contemporáneos de la Justicia Restaurativa y sobre todo introducir nuevas posibilidades de rehabilitación y de seguimiento psico-social. En efecto, por su edad misma los adolescentes infractores son susceptibles de beneficiarse al máximo de intervenciones bien adaptadas a sus dificultades específicas, relacionadas a las graves carencias de su entorno socio-educativo. Lo que necesitan, más que cualesquier otros, son posibilidades serias de inserción social y de inscripción cultural. Más aún, sería imprescindible crear programas educativos adecuados que vengan a contrarrestar los trastornos estructurales inherentes a su desarrollo psicológico y a su socialización en un contexto adverso, aun más deteriorado por efecto de la posmodernidad. Además, habría que fortalecer todo lo que concierne la confrontación del menor con los valores simbólicos de la Justicia en una sociedad cada vez más desprovista de figuras de autoridad, de un ideal común y de un ordenamiento ético.

De ninguna forma, nuestra idea es la de restar importancia a la cuestión de los adolescentes metidos en delincuencia criminal. Pero, el vertiginoso aumento de estos tipos de violencias y agresiones en el mundo presente constituyen ciertamente una de las cuestiones de sociedad más graves de la última década, ya que en lugar de multiplicar las respuestas represivas actuales, el reto debería apuntar a la prevención gracias a la creación de políticas de (re)habilitación e inclusión social eficaces para que la juventud de la marginalidad avanzada

8 Se podría aducir que el sicariato se está volviendo cada vez más una cuestión de adolescentes. Sin embargo, al descartar el criterio de edad y centrarse en el refuerzo de la represión, el único resultado claro sería la disminución de la edad de la actuación criminal hasta los 10 ó ¿por qué no? 8 años, ya que en el plan físico, la mayoría de niños de entre estas edades están plenamente capacitados para cometer crímenes 
reencuentre un lugar digno en la sociedad, un lugar de reconocimiento y de responsabilidad sociocultural.

\section{Lineamientos para una nueva política de inclusión sociocul- tural: la institucionalidad simbólica}

En su estudio, ya citado, Loïc Wacquant, comparando los barrios marginales de Chicago y de París, observa:

El aislamiento de los parias de América es el producto de un proceso activo de abandono [largage] institucional y de segregación (recordemos que segregar significa etimológicamente 'poner de lado') favorecido por el descalabro y la descomposición avanzada del sector público (Wacquant, 2006: 231).

En la actualidad, existen dos opiniones opuestas sobre la cuestión de ¿cómo solucionar el problema de la delincuencia juvenil? La una, guiada por una ideología seguritaria, apunta a una represión ejemplar que sirva de lección a los otros adolescentes con el fin de desanimarles de seguir el camino de sus semejantes; la otra se limita a proponer una mejor participación de los jóvenes al mercado dentro de una ideología posmoderna de consumismo, con más dinero y más comodidad material. Pero ni la una ni la otra toman en cuenta el complejo tema de las carencias psicológicas de la infancia y las distorsiones producidas por un proceso de socialización y de aprendizaje sociocultural sesgado por múltiples privaciones. Sin embargo, tanto una represión como un intento de prevención sin advertir las especificidades subjetivas de los adolescentes marginales, tendrán como consecuencia reforzar la búsqueda de supervivencia como meta esencial de su vida y por ende la opción delictiva cuyo beneficio es relativamente fácil e inmediato. En este sentido, los programas de una verdadera política de inclusión y de (re)habilitación de la juventud marginal no pueden prescindir de una vertiente psicológica que debe abrirse a un trabajo específico respecto a tres elementos principalmente: la elaboración de una noción de espacio de pertenencia para fortalecer la estructuración de la identidad personal, la construcción de un 'ideal' que incluya tanto el reconocimiento de una autoridad 
institucional como la sujetación a una Ley común, y por fin la apropiación de la sociocultura, lo que implica una educación participativa y creativa.

Hablar del espacio en su realidad física puede parecer extraño. Empero, el desarrollo de un sentimiento de pertenencia a un lugar específico donde el adolescente se sienta reconocido, protegido y respetado, donde esté admitido sin restricciones como si fuera un hogar, es una condición esencial para que pueda hacerse sujeto de su actuar y de su devenir en función de una identidad personal consistente. Por este motivo, escuelas, colegios y todos los lugares destinados a acoger a los jóvenes de sectores desfavorecidos deberían estar pensados de esta manera incluyente y transformarse en espacios, donde el adolescente puede aprender a ser responsable de su entorno precisamente porque lo vive como suyo 9 . Sólo en este contexto, el joven podrá empezar a existir como ser autónomo y adquirir la capacidad de expresar sus afectos y sus pensamientos de forma libre, sin temer amenazas o castigos arbitrarios por lo que dice o hace.

Otro elemento esencial es la construcción de un 'ideal', o sea el hecho de compartir un concepto de Bien común, que pasa por la referencia a un 'Padre', alguien a la vez bondadoso y justo, que se preocupe por el joven, el cual a cambio se somete a su autoridad. La tarea de encarnar a esta figura paterna dentro de las distintas instituciones de la sociedad, incumbe a los educadores, profesores y responsables de los jóvenes -debería ser también la función del juez de menores y de quien maneje una función de poder-, aunque en la posmodernidad que denigra todo lo que suena a autoridad y a padre, son cada vez más escasas las personas que aceptan este rol, prefiriendo optar por el papel de amigos o de controladores. A partir del reconocimiento de la metáfora paterna, el camino está abierto para la introyección de la noción de ley, es decir la capacidad de distinguir entre lo permitido y lo prohibído, lo bueno y lo malo, y por fin entre el Bien y el Mal. Entonces el proceso de socialización y el aprendizaje de una convivencia pacífica pueden iniciarse de verdad.

Por fin, la apropiación de una sociocultura en la cual el adolescente se sienta partícipe, una sociocultura con todas sus dimensiones y, en particular, las tra-

9 Cabe notar que la relación al espacio en los lugares de detención para menores infractores tiene gran interés terapéutico por su función de contención psíquica, y pueden servir a elaborar la noción de privacidad -y por ende de identidad- en oposición a los espacios compartidos. 
diciones literarias, la historia y sus relatos, las artes plásticas, la música, y todo el bagaje heredado de las generaciones anteriores, constituye el tercer elemento esencial a la estructuración psíquica de los jóvenes relegados para que tengan acceso a una posición de sujeto responsable de su vida y de su comunidad. Cabe añadir que no se trata solamente de una enseñanza formal sino que el objetivo debe ser en última instancia fomentar la capacidad creadora del adolescente y, de este modo, permitirle sublimar sus impulsos y trasformarlos en producciones valoradas por los otros: eros versus thanatos.

Ciertamente, la orientación actual de la ideología neo-liberal hacia una desimbolización de las insituciones, centrada en metas represivas, no favorece la implementación de una política de esta índole cuya meta sería dar a los jóvenes de la marginalidad avanzada un lugar nuevo de sujetos autónomos y responsables de su devenir y de su mundo. Y el aumento de la delincuencia juvenil por efecto de las circunstancias de una vida cada vez más precaria, parece un medio muy fácil para extremar medidas de exclusión, sin ninguna consideración para el ser humano que las sufre. Pero preferimos escuchar las palabras de uno de los pioneros de la criminología, Étienne De Greeff, y pensar que todavía tienen validez:

El problema criminal no es el problema represivo. La represión esta condenada a quedarse empírica, infantil y sometida a las fluctuaciones de los remolinos de opinión, a quedarse bajo la dependencia de un ministerio cuya mayoría de miembros como los de cualquier gran administración son, a pesar de su cultura, muy alejados de todo lo que concierne su trabajo cotidiano. El problema criminal es otro, sólo se esclarece en medida que se esclarece el misterio del alma humano y sólo puede progresar muy lentamente. Pero progresará y, como sea, la represión tendrá que adaptarse (De Greeff, 1949: 259).

\section{Bibliografía}

BONELLI, Laurent (2010), "Urgences sociales, outrance sécuritaire”, en Le Monde Diplomatique, septembre 2010.

CYRUNLNIK, Boris (2005), Bajo el signo del vínculo, Buenos Aires: Gedisa. 
DE GREEFF, Étienne (1949), Âmes criminelles, Tournai: Casterman.

DESCARGUES-WÉRY, Marie-Antoinette et alter [comps.], (2005), «Présentation», Le malaise adolescent dans la culture, Paris: Éditions CampagnePremière.

DUFOUR, Dany-Robert (2007), El arte de reducir cabezas. Sobre la servidumbre del hombre liberado en la era del capitalismo total, Buenos Aires: Editorial Paidós.

DUPRET, Marie-Astrid (2003), "Exceso de maternidad y descalificación paterna", en Ecuador-Debate, no 59, Quito/Ecuador.

DUPRET, Marie-Astrid (2005), Delincuencia juvenil: Hacia una política de rehabilitación, Quito: Abya-Yala.

ELIADE, Mircea (1992), Initiation, rites, sociétés secrètes, Paris: Gallimard.

ESPOSITO, Roberto (2003), Communitas. Origen y destino de la comunidad, Buenos Aires: Amorrortu editores.

GREEN, André (1981), “Átomo de parentesco y relaciones edípicas”, en LéviSRAUSS, Claude, Seminario: La identidad, Barcelona: Ediciones Petrel.

INHELDER, Barbel y Jean Piaget (1985), De la lógica del niño a la lógica del adolescente. Ensayo sobre la construcción de las estructuras operatorias formales, Barcelona: ediciones Paidós.

JEAMMET, Philippe (2005), Le monde adulte en mal de transmission, Entrevue con Philippe Jeammet, en 'Faire Autorité?', Esprit n.313.

JEAN, Jean-Paul (2008), Le système pénal, Paris: Éditions La Découverte.

LACAN, Jacques (1966), Écrits, Paris: Seuil.

LEBRUN, Jean-Pierre (2004), Les désarrois nouveaux du sujet. Prolongements théorico-cliniques au Monde sans limite, Paris: Érès.

LEAITRE, Véronique (2005), "Les présupposés du concept de recours à l'acte: Confrontation avec les données de la clinique périnatale", Balier, Claude et alt. [comps.], La violence en Abyme, Paris: Presses Universitaires de France.

LEMPP, Reinhart (1979), Delincuencia Juvenil: Análisis de ochenta casos de homicidio. Barcelona: Herder. 
MADAR, Chase (2010), "New-York remet en cause le tout-sécuritaire à l'école", en Le Monde Diplomatique, juin 2010.

MARCELLI, Daniel y Alain Braconnier (1988), Psychopathologie de l'adolescent, Paris: Masson.

MELMAN, Charles (1992), "Les adolescents ont toujours affaire au Minotaure", en Le Bulletin Freudien, Revue de l'Association Freudienne de Belgique $\mathrm{n}^{\circ} 19$.

MELMAN, Charles (2005), El hombre sin gravedad. Gozar a cualquier precio, Entrevista con Jean-Pierre Lebrun, Rosario: Universidad Nacional de Rosario.

SCHMOUCHKOVITCH, Michel (1995), "La Psychopathologie du parricide", en L'Évolution Psychiatrique, 60, année 1995, Paris: Dunod.

UNDA Lara, René (2010), Jóvenes y juventudes. Acción, representaciones y expectativas sociales de jóvenes en Quito, Quito: Abya-Yala.

VYGOTSKI, Lev (1985), Pensée et langage, Paris: Terrains / Éditions sociales.

WACQUANT, Loïc (2006), Parias urbain. Ghetto, banlieues, État, Paris: Éditions La Découverte.

ZEA, Cornelius (2007), Pandillas Juveniles y Violencia. Estudio de agrupaciones pandilleras, ubicadas en la Parroquia Eloy Alfaro del Distrito Metropolitano de Quito. Tesis para obtener el título de Magíster en Política para Promoción de la Infancia y Adolescencia.

*Todas las traducciones de citas de libros en francés son nuestras.

Envío 29 de septiembre/2010 - aceptación 25 de octubre/2010 